\title{
Dilemas do Reconhecimento: apresentação ao artigo de Nancy Fraser
}

\author{
Heloisa Buarque de Almeida
}

The recognition dimension corresponds to the status order of society, hence to the constitution, by socially entrenched patterns of cultural value, of culturally defined categories of social actors - status groups - each distinguished by the relative honor, prestige and esteem it enjoys vis-à-vis the others. The distributive dimension, in contrast, corresponds to the economic structure of society, hence to the constitution, by property regimes and labor markets, of economically defined categories of actors, or classes, distinguished by their differential endowments of resources (Fraser 2000: 117).

Nancy Fraser é professora de Ciência Política da New School de Nova Iorque, onde leciona disciplinas de teoria social e política e teoria feminista. Ainda pouco de sua produção foi traduzida para o português. Apresento aqui - a convite da Cadernos de Campo e de Júlio Simóes - alguns comentários sobre seu trabalho e os temas que trata no artigo que segue. Para a antropologia, sua problematizaçáo da cultura como um lugar de disputas por definiçóes, de luta por sentidos simbólicos e de perigosas reificaçóes (essencializantes) é um tema de extrema relevância.

A reflexão de Nancy Fraser parte de duas vertentes: da Teoria Crítica e sua análise sobre participaçáo política, democracia, justiça, sociedade civil e esfera pública, com foco na questáo da desigualdade de classes; e por outro lado, da teoria feminista e de gênero pós-estruturalista. Um exemplo da proposta crítica de Fraser é sua análise do trabalho de Habermas, em "O que é crítico na teoria crítica? Haber-

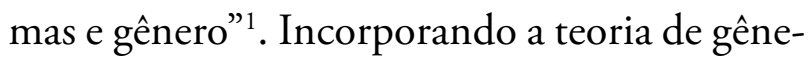
ro, Fraser analisa, discute e desconstrói alguns conceitos da Teoria Crítica, demonstrando os subtextos de gênero que atuam nas definiçóes propostas por Habermas. Tal se dá, por exemplo, a partir da suposta oposiçáo de "tipos naturais" entre a reprodução material e a reprodução simbólica - esta última relacionada ao trabalho feminino invisível e não remunerado de cuidar das crianças, que ela destaca como trabalho também material e não apenas simbólico. Uma série de categorias e definiçóes de Habermas que se desdobram desta primeira distinção são revistas em seu texto, como a distinção entre "contextos de ação socialmente integrados" e "contextos de ação sistemicamente integrados". A reflexão sobre a própria ciência remete a Foucault. Fraser, como grande parte das teóricas contemporâneas sobre o gênero, revela esta evidente inspiração teórica em seu trabalho.

Nos anos 90, diante do fim do socialismo, da intensificação dos processos de globalização e da visibilidade da presença da política das identidades no âmbito dos movimentos sociais, o pensamento social e a teoria política passaram a enfrentar de forma crescente os outros eixos de desigualdade social para além das classes. Nancy Fraser já refletia sobre a questão a partir da teoria de gênero.

1. Publicado em Benhabib \& Cornell (1987: 31-55). Há uma versão portuguesa na revista Ex Aequo, da Associação Portuguesa de Estudos sobre as Mulheres, de 2003. Nesta coletânea e neste número da revista encontram-se trabalhos de outras autoras com quem Fraser dialoga e debate intensamente, como Carole Patemen, Seyla Benhabib, Iris Young e Judith Butler. 
As analogias entre a teoria de gênero e aquelas questôes trazidas pelas diferenças raciais, étnicas e culturais se tornam evidentes. Movimentos sociais recrudescem na defesa de determinadas identidades, por um lado, ao passo que a teoria pós-estruturalista questiona a essencialização destas identidades promovidas pelo movimento social e pelo senso comum, demonstrando como são construtos sociais, políticos e históricos, e desnaturalizando alguns de seus aspectos. Na teoria de gênero anglo-saxã esta questão torna-se evidente e ponto central de reflexão de algumas autoras (como Judith Butler, com quem Fraser mantém um longo debate). Mesmo quando tais teóricos estão comprometidos com o movimento político, ou seja, defendem uma prática política feminista ou anti-racista, a teoria provoca dilemas e impasses para o movimento, pois este se baseia em categorias unificadas, como "mulher" ou "negro". Ademais, mesmo no âmbito dos movimentos sociais tais categorias foram problematizadas pela percepção de um mundo social marcado por múltiplas diferenças e desigualdades - de classe, "raça", etnia ou cultura, gênero, sexualidade, entre outros. Esta percepçáo coloca novos dilemas para os movimentos sociais, mas também para a teoria de gênero, para os estudos sobre raça e para a teoria social.

O texto de Fraser que é traduzido a seguir ${ }^{2}$ insere-se em um debate mais amplo da autora com Axel Honneth, que, ao lado de Charles Taylor, reforça que a questáo central do mundo contemporâneo é a luta por reconhecimento ${ }^{3}$.

2. A primeira versão, mais longa do que esta tradução, foi publicada em 1995, e uma versão ainda mais expandida está em seu livro Justice Interruptus: Critical Reflections on the "Postsocialist" Condition (1997).

3. O debate entre Honneth e Fraser é explicitado no livro de Nancy Fraser \& Axel Honneth, Redistribution or Recognition? A Political-Philosophical Exchange ([1998] 2003). O trabalho de Honneth tem também uma traduçâo para o português, intitulado Luta por Reconhecimento (Honneth 2003).
Fraser propóe no artigo que o foco esteja nas duas dimensóes. Por um lado na justiça econômica pela redistribuição, e por outro no reconhecimento cultural e o devido respeito às diferenças. Trata-se de uma distinção analítica entre dois campos: um mais propriamente da economia política e outro cultural, embora ela considere as correlaçóes entre eles. Fraser destaca neste e noutros trabalhos que não é possível excluir do debate a dimensão da desigualdade econômica e de classes no sentido estrito, e afirma que esse tema estaria perdendo espaço na agenda política e teórica contemporânea com o fim do socialismo e a crescente ampliação do processo de globalização. Mais do que isso, a autora defende que o apagamento da questáo de classe estaria sendo impulsionado por uma visão que tende a negar o problema da desigualdade econômica e de classes como se ela pudesse ser superada no mundo do consumo e das especificidades identitárias, e como se tal não fizesse mais sentido num mundo "pós-socialista”. Para Fraser é preciso ter um modelo bidimensional em termos analíticos, mesmo que na prática tal distinção seja difícil e ainda que seja evidente que em vários exemplos empíricos a desvalorização cultural de um grupo esteja diretamente relacionada a seu acesso a recursos e direitos, ao passo que seu menor acesso a recursos promova uma construção simbólica como um grupo que "vale menos". A distinção é mais evidente nos exemplos opostos de movimentos sociais calcados na diferença de classe - com foco na questão da distribuição de maneira mais evidente, embora contemple o componente cultural -, por oposição ao exemplo dos movimentos calcados na sexualidade, como o movimento homossexual - cujo foco seria o reconhecimento, embora sua desvalorização cultural afete seu acesso a direitos, como direitos relativos ao casamento.

Outro aspecto relevante deste artigo é a aproximação evidente entre gênero e "raça", 
pois são ambos exemplos de coletividades bivalentes que revelam tanto problemas de redistribuição como de reconhecimento. A distinção lhe parece mais fundamental quando discute os remédios para compensar tais demandas e suas complexidades - o remédio para redistribuição reforçaria a igualdade, ao passo que o remédio para o reconhecimento marcaria a diferença e a especificidade do grupo. A aproximação entre gênero e raça também é feita teoricamente pela desnaturalização e desconstrução das diferenças, quer seja pela desconstrução do sexo operada pelo próprio conceito do gênero, ou pela desconstrução da "raça" ou da identidade étnica. Este texto revela como Fraser agrega a uma mesma proposta teórica aspectos centrais advindos da Teoria Crítica e a contribuição específica do pós-estruturalismo.

Noutro artigo, "Rethinking Recognition" (maio-junho 2000), Fraser reflete como as demandas por reconhecimento podem variar desde movimentos emancipatórios até a forma perversa como a noção de uma identidade cultural reificada e essencializada é usada em campanhas de "limpeza étnica" e genocídio (os exemplos são a guerra dos Bálcãs e Ruanda). Neste trabalho, ela pergunta por que os conflitos teriam tomado esta forma e por que movimentos táo variados teriam baseado suas demandas no idioma do reconhecimento e da identidade apenas. Problematizam estas formas reificadas de identidade, construçóes que servem a violentas açóes de padronização de uma comunidade que náo aceita dissensos internos e nega o respeito à diferença. $\mathrm{O}$ que me parece mais interessante para a antropologia é que, ali, sua proposta descola o reconhecimento da questáo da identidade, e aproxima-se da problemática da cultura e de suas formas valorativas. Naquele texto, assim com no ensaio aqui traduzido por Júlio Simóes, o problema do reconhecimento está atrelado a uma versão não unitária, não unívoca e não consensual de cultura. "A cultura é um terreno legítimo e mesmo necessário de disputas, um espaço de injustiça em si mesmo, e fortemente imbricado com a desigualdade econômica" (: 109). Cultura não é um todo fechado, nem uma unidade. É um lugar de disputas de sentido, associadas a formas de desigualdade econômica e política. Há sentidos que podem desvalorizar e colocar alguns indivíduos em posiçóes sociais desfavoráveis. Em "Rethinking Recognition”, Fraser destaca que está usando o conceito de classe social no sentido de status de Weber. Relaciona a questão do reconhecimento ao status individual e ao acesso às formas de poder. "A dimensão do reconhecimento (...) refere-se à subordinação de status, enraizada em padróes institucionalizados de valor cultural" (: 117). O não-reconhecimento (misrecognition) torna-se uma forma institucionalizada de subordinação.

Os sentidos dados ao feminino, à negritude, à pobreza, à homossexualidade, podem assim afetar as formas institucionais - como as leis propriamente, que podem invisibilizar tais grupos, gerando e promovendo desigualdade de acesso a direitos. A cultura construída na sociedade contemporânea é marcada por formas de desigualdades e de "naturalização" destas em categorias culturais, mesmo em instituiçôes e formatos como a própria ciência, que não pretendem ser discriminatórios.

O texto aqui traduzido é uma boa introdução a sua análise bidimensional: para usar termos foucaultianos, a materialidade é também produzida pelo discurso (cultura). Mas para Fraser materialidade e discurso nem sempre estão coladas de modo evidente, necessitam de um olhar analítico que os distingam, pelo menos em teoria, e que busque interpretar suas formas de interação. Esta distinção lhe parece central para náo se correr o risco de deslocar o problema da redistribuição, escondendo-o ou marginalizando-o sob a crescente valorização do reconhecimento. 


\section{Referências bibliográficas}

BENHABIB, Seyla; CORNELL, Drucilla. 1987. Feminism as Critique: on the politics of gender. Minneapolis: University of Minnesota Press.

FRASER, Nancy. 2003. O que é crítico na teoria crítica? Habermas e gênero. Ex Aequo: reconceptualizaçôes filosóficas e de teoria política (perspectivas feministas), n. 8 .

1987. "What's Critical about Critical Theory? The Case of Habermas and Gender". In: BENHABIB, Seyla; CORNELL, Drucilla. Feminism as Critique: on the politics of gender. Minneapolis: University of Minnesota Press, pp. 31-55.
1996. From redistribution to recognition?: $\mathrm{Di}-$ lemmas of justice in a "postsocialist" age. New Left Review, n. 212, pp. 68-93, jul./ago. . 1997. Justice Interrupturs: Critical Reflections on the "Postsocialist" Condition. New York: Routledge. . 2000. Rethinking Recognition. New Left Review, n. 3, pp. 107-120, maio/jun.

FRASER, Nancy; HONNETH, Axel. 2003. Redistribution or Recognition?: A political-philosofical exchange. London: Verso.

HONNETH, Axel. 2003. Luta por reconhecimento. São Paulo: Editora 34.

\section{autor Heloisa Buarque de Almeida}

Professora do Departamento de Antropologia / USP

Editou a Cadernos de Campo $\mathrm{n}^{\text {os }} 1$ a 3

Recebido em 22/12/2006

Aceito para publicação em 22/01/2007 